At the age of 7 years she is well and development is normal. Her height of $108.3 \mathrm{~cm}$ and weight of 16.4 $\mathrm{kg}(89 \%$ height for age, $70 \%$ weight for age, and $88 \%$ weight for height) both lie below the third centile. Her electrolyte concentrations are variable, but usually normal with daily oral supplements adjusted on regular electrolyte values. There is no evidence of rickets. The talipes equinovarus has responded to serial splinting and physiotherapy and she walks normally. Her chest radiograph is within normal limits with a Chrispin-Norman score of 3.

\section{Discussion}

Renal tubular acidosis is a syndrome characterised by systemic hyperchloraemic acidosis with inappropriately high urine $\mathrm{pH}$, excessive urinary sodium bicarbonate excretion, and normal glomerular function. In the distal tubular type the urinary $\mathrm{pH}$ remains high during severe acidosis (blood $\mathrm{pH}$ less than 7.2). In contrast patients with proximal renal tubular acidosis can acidify their urine in severe acidosis, and the complex dysfunction of the proximal tubule characteristic of Fanconi's syndrome is absent. Although there is bicarbonate wastage in distal renal tubular acidosis, it is usually less than $8 \%$ of the fraction of filtered bicarbonate, and the acidosis can be corrected with small amounts of sodium bicarbonate.

This child had an inappropriately alkaline urine in the presence of severe acidosis. There is no doubt that she also has cystic fibrosis. The association of these two inherited conditions in the same patient may be a chance finding illustrating the increased occurrence of complex metabolic problems in children of consanguineous marriages. Electrolyte disturbances from a number of causes are common in patients with cystic fibrosis and should be considered in such circumstances. Decreased electrolyte concentrations and profound alkalosis in patients with cystic fibrosis caused by chronic loss of sweat electrolytes and mild gastrointestinal disturbances have been reported. ${ }^{4}$ Decreased electrolyte concentrations caused by sweat losses in hot weather have been reported after the original observations by di Sant' Agnese et al. ${ }^{5}$ In addition to excessive losses both modern low solute milks and breast feeding may lead to an inadequate net electrolyte intake in the infant with cystic fibrosis. ${ }^{6}$

Our patient was unusual because her reduced electrolytes were accompanied by severe acidosis with serum and urinary electrolytes compatible with a profound renal tubular disorder. Finally, in children with an inherited disorder whose parents are first cousins (as are $60 \%$ of the Asian population in our area) an additional recessive condition should be suspected if the clinical picture of a disorder is atypical or the response to treatment unsatisfactory.

\footnotetext{
References

1 Robson AM, Tateiski S, Ingelfinger JR, Strominger DB, Klahr S. Renal function in patients with cystic fibrosis. $J$ Pediatr 1971;79:42-50.

2 Mearns RC, Sebastian A, McSherry E. Renal acidosis. Kidney Int 1972;1:322-40.

${ }^{3}$ Sarshcer EJ, Breslaw JL. Cystic fibrosis: a disorder of calcium stimulated secretion and transepithelial sodium transport. Lancet $1982 ; \mathbf{i}: 368-70$.

${ }^{4}$ Beckerman RC, Taussig LM. Hypoelectrolytemia and metabolic alkalosis in infants with cystic fibrosis. Pediatrics 1979;63:580-3.

5 di Sant' Agnese PA, Darling RC, Peresa GA. Sweat electrolyte disturbances associated with childhood pancreatic disease. Am J Med 1953;15:777-84.

${ }^{6}$ Laughlin JJ, Brady MS, Eigan H. Changing feeding trends as a cause of electrolyte depletion in infants with cystic fibrosis. Pediatrics 1981;68:203-7.
}

Correspondence to Dr EJ Simmonds, Regional Cystic Fibrosis Unit and Department of Paediatrics, St James's University Hospital, Leeds LS9 7TF.

Accepted 8 December 1988

\title{
Diffuse nephrocalcinosis and idiopathic renal hypercalciuria
}

\author{
V K AGGARWAL AND K VERRIER JONES
}

Department of Renal Medicine, Royal Infirmary, Cardiff

SUMMARY A 12 year old boy presented with primary nocturnal enuresis. Investigation showed extensive bilateral nephrocalcinosis of no obvious or recognised cause. Persistent severe renal hyper- calciuria was confirmed by an intravenous calcium infusion. Idiopathic hypercalciuria is not a common cause of nephrocalcinosis and has not previously been described in a child. 


\section{Case report}

A 12 year old boy presented to his general practitioner with primary nocturnal enuresis. His father had a similar problem that resolved at 16 years of age, and an uncle had childhood urinary tract infection and a left duplex kidney. Because of this history an intravenous pyelogram was carried out, which showed extensive renal calcification of medulla and pyramids (fig 1). He was therefore referred to the children's renal clinic for investigations.

Further enquiry elicited that he had always enjoyed good health and had become continent during the daytime at 2 years of age. On direct questioning he admitted to having mild polyuria and polydypsia, but these did not interfere with his daytime activities or sleep at night. On examination he looked well but was mildly obese (height-75th percentile, weight-97th percentile) and showed signs of early puberty (Tanner stage 2). His blood pressure was $130 / 80 \mathrm{~mm} \mathrm{Hg}$. Systemic examination did not show any abnormality.

Results of investigations were as follows (normal

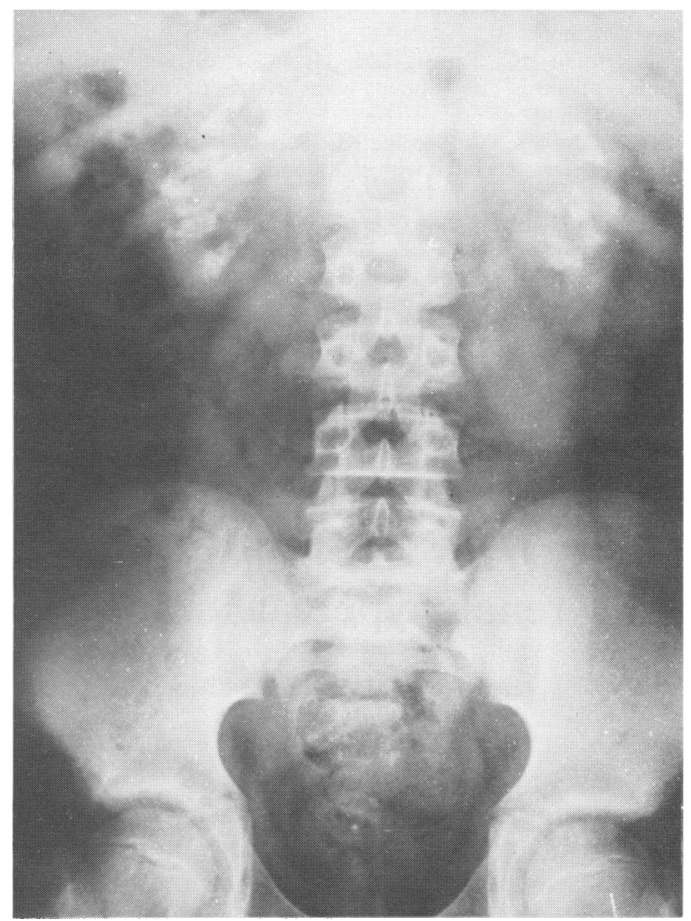

Fig 1 Plain abdominal radiograph showing extensive renal calcification of medulla and pyramids. ranges in parentheses): haemoglobin concentration $154 \mathrm{~g} / \mathrm{l}$; total serum calcium concentration $2.35 \vec{\Rightarrow}$ $\mathrm{mmol} / \mathrm{l}(2 \cdot 25-2 \cdot 60)$; ionised calcium $1.24 \mathrm{mmol} / \mathrm{l} \stackrel{\text { ? }}{\rightarrow}$ $(1 \cdot 17-1 \cdot 29)$; inorganic phosphate $1.36 \mathrm{mmol} / 1(0 \cdot 80$ - 등 1.45); albumin $46 \mathrm{~g} / 1$ (35-50); alkaline phosphatase $\frac{\bar{\sigma}}{\overline{0}}$ activity $459 \mathrm{IU} / \mathrm{l}(<400)$; plasma sodium concentra- $\frac{\widehat{\sigma}}{\overrightarrow{0}}$ tion $141 \mathrm{mmol} / \mathrm{l}$; potassium $3.8 \mathrm{mmol} / \mathrm{l}$; urea $10.4 \stackrel{\AA}{\varrho}$ $\mathrm{mmol} / \mathrm{l}$; bicarbonate $23.5 \mathrm{mmol} / \mathrm{l}$; creatinine 95 \% $\mu \mathrm{mol} / 1$ (42-72); magnesium $0.6 \mathrm{mmol} / \mathrm{l}(0.6-0.9)$; $\overrightarrow{0}$ and uric acid $0.38 \mathrm{mmol} / \mathrm{l}(<0 \cdot 4)$. Intact serum parathyroid hormone measured by two site im- $\vec{\omega}$ munochemiluminometric assay was $10.8 \mathrm{pmol} / 1$ 品 $(0 \cdot 9-5 \cdot 4)$. Glomerular filtration rate measured with edetic acid labelled with ${ }^{51} \mathrm{Cr}$ was $52 \mathrm{ml} /$ minute $/ 1.73$ $\mathrm{m}^{2}$ surface area $(88-175)$.

Urine examination showed no evidence of glycosuria, proteinuria, haematuria, or aminoaciduria. Microscopy of the urine showed no red cells or casts, and culture showed no pathogens. Fasting and $\frac{9}{3}$ postprandial calcium creatinine ratio done on $\vec{c}$ several occasions was between 0.9 and $1.5 \mathrm{mmol} / \subseteq$ mmol $(<0 \cdot 6)$. A 24 hour calcium excretion test performed on three occasions, showed calcium $\vec{\ominus}$ excretion of 10.4 to $10.8 \mathrm{mmol} /$ day or $0.2 \mathrm{mmol} / \mathrm{kg} /{ }^{\circ}$ 24 hours $(<0 \cdot 1 \mathrm{mmol} / \mathrm{kg} / 24$ hours $)$. Twenty four hour urine oxalate excretion was 20 to $25 \mathrm{mg} /$ day/ $1.73 \mathrm{~m}^{2}$ surface area (29-50). These results were confirmed by a reference laboratory. Following treatment with ammonium chloride $(0.1 \mathrm{~g} / \mathrm{kg}$ body weight), urinary $\mathrm{pH}$ dropped to 5.4 at five hours, and 5.3 at six hours. Ultrasound examination of the kidneys confirmed extensive nephrocalcinosis but also showed in addition cortical calcification to the medulla. Radiography of the left hand and wrist showed no abnormality.

Oral hydrochlorthiazide $1 \mathrm{mg} / \mathrm{kg}$ for two months failed to influence his calcium excretion. Intravenous infusion of calcium gluconate $(1.25 \mathrm{mg} / \mathrm{kg}$ over 35 minutes showed suppression of intact serum parathyroid hormone (fig 2). Although there was no significant rise in the serum calcium concentration there was a significant increase in calcium excretion in the urine. There was no evidence of hypercalciuria in first degree relatives.

\section{Discussion}

The three most frequent causes of generalised 0 nephrocalcinosis are hypercalcaemia, defects in urine acidification, and hyperoxaluria. ${ }^{1}$ Familial $\mathbb{\varnothing}$ juvenile nephronophthisis or medullary cystic dis-? ease may show some degree of nephrocalcinosis and hypercalciuria. The other rare causes include treatment with diuretics, Bartter's syndrome, and hypomagnesaemia. Idiopathic hypercalciuria is a $\stackrel{\mathbb{D}}{2}$ common condition. Most cases are asymptomatic, 


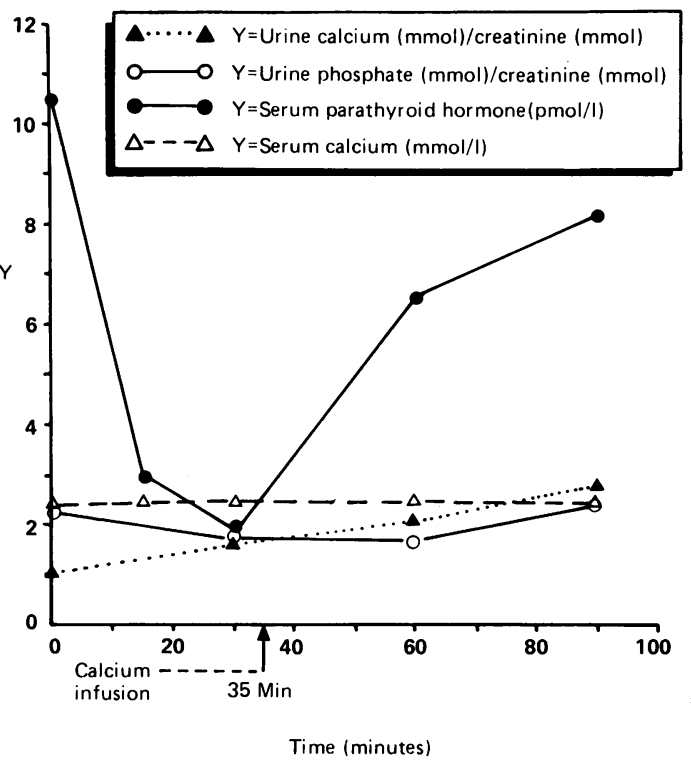

Fig 2 Calcium loading test showing calcium infusion $(1.25 \mathrm{mg} / \mathrm{kg}$ body weight) given over 35 minutes that suppressed high parathyroid hormone concentrations and although there was no appreciable rise in serum calcium, urine calcium excretion increased significantly.

some of them present with persistent or recurrent haematuria, ${ }^{23}$ or urolithiasis. ${ }^{4}$ Recently many other urinary tract disorders ${ }^{5}$ such as dysuria, frequency, and enuresis have been described secondary to idiopathic hypercalciuria, but in these cases the threshold for diagnosing hypercalciuria is rather low. Diffuse nephrocalcinosis caused by idiopathic hypercalciuria has not been described.

All the known causes of generalised nephrocalcinosis have been excluded and the diagnosis of familial juvenile nephronophthisis or medullary cystic disease are unlikely considering the clinical presentation and severity of nephrocalcinosis. In our case it was shown that hypercalciuria is caused by a renal tubular leak as both fasting and postprandial urine samples showed excessive calcium excretion, and on calcium infusion urine calcium excretion increased tremendously, although serum concentrations did not rise appreciably. Intact serum parathyroid hormone concentrations may be raised secondarily in idiopathic renal hypercalciuria ${ }^{6}$ as a reflection of the urinary calcium leak, and they can be suppressed by calcium loading, which was also shown in this case by the calcium infusion test. Hydrochlorthiazide can suppress calcium excretion in cases of idiopathic hypercalciuria but it is effective in only about $70 \%$ of cases. In this case it seems both conditions were related and hypercalciuria is not simply an epiphenomenon. The problem of nocturnal enuresis has been successfully managed by toilet training and at present the patient has been advised to take a low sodium and high fibre diet hoping to decrease hypercalciuria and hence avoid further renal damage. During the period of follow up (eight months) he has remained healthy although his renal function is deteriorating slowly.

We would like to thank Dr P Lucas, Lecturer in Renal Medicine, for his help and Miss J Cook for secretarial help.

\section{References}

${ }^{1}$ Cremin B, Wiggelinkhuisen J, Bonnici F. Nephrocalcinosis in children. Br J Radiol 1982;55:413-8.

2 Stapleton FB, Roy S III, Noe HN, Jerkins G. Hypercalciuria in children with haematuria. $N$ Engl J Med 1984;310:1345-8.

${ }^{3}$ Kalia A, Travis LV, Bronhard BH. The association of idiopathic hypercalciuria and asymptomatic gross hematuria in children. $J$ Pediatr 1981;99:716-9.

4 Coe FL, Favus MJ. Disorders of stone formation. In: Brenner BM, Rector FC, eds. The kidney. 3rd ed. Philadelphia: W B Saunders, 1986:1403-12.

5 Heiliczer JD, Canonigo BB, Bishof NA, Moores ES. Noncalculi urinary tract disorders secondary to idiopathic hypercalciuria in children. Pediatr Clin North Am 1987;34:711-18.

${ }^{6}$ Coe FL, Canterbury JM, Firpo JJ, et al. Evidence for secondary hyperparathyroidism in idiopathic hypercalciuria. J Clin Invest 1973;52:134-6.

Correspondence to Dr VK Aggarwal, Department of Renal Medicine, Royal Infirmary, Cardiff CF2 1SZ.

Accepted 16 January 1989 